\title{
Dual Satellite Operations in Close Formation Flight
}

\author{
E. Maurer ${ }^{1}$, S. Zimmermann ${ }^{2}$, F. Mrowka ${ }^{3}$, H. Hofmann ${ }^{4}$ \\ German Aerospace Center (DLR), Oberpfaffenhofen, Germany, 82234
}

\begin{abstract}
TerraSAR-X (TSX) and TanDEM-X (TDX) are two satellites flying in low-earth orbit. Both satellites are equipped with a synthetic aperture radar (SAR) payload for Earth observation. TSX has been launched in 2007 and TDX in 2010. Both satellites are operated by the German Space Operations Center (GSOC). Since October 2010 the two spacecraft are orbiting the Earth in a close formation flight with inter-satellite distances in the order of a few hundred meters. In this configuration the two satellites fulfill the goals of two different missions: The "TerraSAR-X" mission uses the radar instrument on either TSX or TDX satellite in stand-alone mode. The "TanDEM-X" mission uses the radar instrument on both satellites simultaneously in so-called "bi-static" mode. The former application delivers two dimensional images, the latter allows a three dimensional model of the Earth's surface to be made. During the TanDEM-X mission a digital elevation model covering the Earth's complete land mass is generated. This paper describes several aspects of the combined missions from the control center's point of view. The workflow of dual satellite operations includes safety measures required to minimize the risks in close formation. In particular, protection against potential collision of the two spacecraft and protection against illumination of the partner satellite during radar beam transmission must be guaranteed. Furthermore, the concept of the mission planning system which distributes the payload requests of two different missions to two satellites will be presented.
\end{abstract}

\section{Nomenclature}

$\begin{array}{ll}\text { TSX } & =\text { TerraSAR-X satellite } \\ \text { TDX } & =\text { TanDEM-X satellite } \\ \text { TerraSAR-X } & =\text { TerraSAR-X mission } \\ \text { TanDEM-X } & =\text { TanDEM-X mission } \\ \text { TT\&C } & =\text { Telemetry, Tracking and Command } \\ \text { LEOP } & =\text { Launch and Early Orbit Phase } \\ \text { MPS } & =\text { Mission Planning System } \\ \text { DEM } & =\text { Digital Elevation Model }\end{array}$

\section{Introduction}

$\mathrm{T}$ erraSAR-X and TanDEM-X are two combined missions on two satellites (TSX and TDX) in low-earth orbit. Initially, the TerraSAR-X mission has been designed as a single satellite mission for Earth observation by synthetic aperture radar remote sensing. The TanDEM-X mission has been implemented as an add-on to the TerraSAR-X mission. In the context of the TanDEM-X mission TDX, a second nearly identical satellite to TSX, has

\footnotetext{
${ }^{1}$ TerraSAR-X/TanDEM-X project lead at GSOC, German Space Operations Center, Oberpfaffenhofen, 82234 Wessling, Germany/ Edith.Maurer@dlr.de.

${ }^{2}$ TerraSAR-X/TanDEM-X flight operations manager, German Space Operations Center, Oberpfaffenhofen, 82234 Wessling, Germany/ Steffen.Zimmermann@dlr.de.

${ }^{3}$ TerraSAR-X/TanDEM-X flight operations manager / Mission Planning Team Lead at GSOC , German Space Operations Center, Oberpfaffenhofen, 82234 Wessling, Germany/ Falk.Mrowka@dlr.de.

${ }^{4}$ Former TerraSAR-X/TanDEM-X project lead at GSOC, German Space Operations Center, Oberpfaffenhofen, 82234 Wessling, Germany/ Harald.Hofmann@dlr.de.
} 
been launched and has been maneuvered into close formation flight with TSX. The proximity of the satellites allows the combination of both synthetic aperture radar instruments to perform single pass radar interferometry.

\section{TerraSAR-X mission:}

The synthetic aperture radar can be operated in several imaging modes and offers a wide field of application, for example in hydrology, geology, climatology, oceanography, environmental monitoring, disaster monitoring and research in remote sensing techniques ${ }^{1}$. Since the mission is funded in a public private partnership (PPP), TerraSAR$\mathrm{X}$ mission data are offered on commercial market by Astrium GeoInformation (http://www.astrium-geo.com/) and are provided to the scientific community by DLR (http:///sss.terrasar-X.dlr.de/). TSX was launched in June 2007. The operational phase of the TerraSAR-X mission started in January 2008 after half a year of commissioning. A description

of the TerraSAR-X hardware can be found in Ref 2. Two dimensional basic products for TerraSAR-X mission users are delivered in different imaging modes $^{3}$ :

1) Scan-SAR mode: $18 \mathrm{~m}$ resolution , 100*150 km scene size

2) Strip Map mode: 3-m resolution, $30 \mathrm{~km}$ x $50 \mathrm{~km}$ scene size

3) Spotlight Mode: $1.7 \mathrm{~m}$ resolution, $10 \mathrm{~km} \times 10 \mathrm{~km}$ scene size

4) High Resolution Spotlight Mode: $1 \mathrm{~m}$ resolution, $10 \mathrm{~km} \times 5 \mathrm{~km}$ scene size

5) Further experimental modes

The TanDEM-X mission (TerraSAR-X add-on for Digital Elevation Measurement):

The primary mission goal of the TanDEM-X mission is, as already indicated by the abbreviation, the generation of a digital elevation model with unprecedented accuracy according to the HRTI-3 (High-Resolution Terrain information $)^{5}$ specifications. A data set covering the Earth landmass with a $12 \mathrm{~m}$ horizontal and a $2 \mathrm{~m}$ vertical resolution shall be collected within 3 years ${ }^{4}$. Height information is obtained by combining the radar instruments on TSX and TDX by the technique of single pass interferometry ${ }^{6}$. In bi-static imaging mode the radar beam is transmitted by one active satellite, whereas back-scattered signal from the Earth's surface is recorded by both. The desired resolution of HRTI-3 specification requires a very good knowledge of the baseline. This translates in a requirement that the inter-satellite distance is measured to within $1 \mathrm{~mm}$. This is actually achieved as demonstrated by Montenbruck et al. ${ }^{7}$ Furthermore the possibility of adjusting the inter satellite distances between TSX and TDX qualifies the formation as the first configurable SAR-interferometer in space opening up new perspectives for remote sensing technique research ${ }^{5}$. TDX was launched in June 2010 and subsequently it approached TSX satellite. The first formation was established in October 2010.

The sending of a radar signal puts a considerable strain on the satellites' thermal-power system. Radar operations are therefore limited to 210s per orbit on average. Bi-static TanDEM-X missions acquisitions compete for resources with mono-static TerraSAR-X mission acquisition (on-board memory and limitation of the SAR operations time are the bottle-necks). As compensation for the reduction TerraSAR-X mission resources on TSX, roughly half of TerraSAR-X mission datatakes are performed by TDX. Earth target scene location for TerraSAR-X mission datatakes performed by TSX and TDX are required to be identical. In order to compensate for the Earth target scene geo location shift resulting from the inter satellite distance a periodic roll motion is applied on TDX.

The TerraSAR-X and TanDEM-X ground segment is split into three parts provided by DLR at the site of Oberpfaffenhofen near Munich. Operations of TSX and TDX are performed by the German Space Operation Center. Payload data downlink reception, processing distribution and archival as well as the delivery are performed by the DLR Earth Observation Center ${ }^{3}$. Radar instrument operations of TSX and TDX ${ }^{3}$ and the generation of the TanDEM$\mathrm{X}$ acquisition plan are carried out by the DLR Microwave and Radar Institute ${ }^{8}$. Both TSX and TDX were built by Astrium GmbH. A description of the satellites' hardware can be found in the work of Pitz and Miller $2010^{2}$ and Giese and Ulrich $2011^{9}$.

The main operational challenges in the TerraSAR-X / TanDEM-X missions are from the control center's point of view: 
1) The combination of two missions on two satellites

2) The Integration of the TanDEM-X mission in the already operational TerraSAR-X mission

3) Close Formation flight over long intervals with necessary safety measures

The following terminology will be used in order to distinguish between the missions and the satellites: TSX refers to the satellite launched in 2007 and TDX to the one launched in 2010. The term "TerraSAR-X mission" always refers to the generation of $2 \mathrm{D}$ acquisition for a commercial and scientific user community. These data takes can be made on both TSX and TDX. "TanDEM-X mission" denotes the interferometric measurements whereby both spacecraft are used to systematically create a 3D image of the land mass of the Earth.

\section{Dual Satellite and Dual Mission Operations Concept}

The basic operations concept is to handle TSX and TDX operations independently as far as possible. TSX and TDX spacecraft are nearly identical from hard- and soft-ware point of view. There is no master/slave configuration between both spacecraft but an equal level operations approach. Figure 1 shows a simplified work flow for TSX and TDX operations in the control center. Each satellite, TSX and TDX, has a dedicated TT\&C link from ground to space. There is no tele-command routing from one spacecraft to the other and also no complete telemetry routing. As described in chapter IV there is an exception for a dedicated telemetry packet which is sent from TSX to TDX via an inter satellite link. The spacecraft' monitoring and control systems are based on two independent instances of DLR's SCOS version, based on ESA's SCOS 3.1 application. Since TT\&C contacts of both satellites are frequently parallel in time, two operator shifts, one for each satellite, are taking care of the routine operations tasks in the control room. After the TDX LEOP and early commissioning both TSX and TDX monitoring and control systems have been integrated in a combined control room. In contrast to the satellite specific first level operator support, second level support performed by the subsystem and system engineer team and 24/7/365 on-call support is combined for both satellites. 
Flight Dynamics is a combined system for both missions/satellites since close formation flight requires absolute and relative orbit control. The TerraSAR-X mission has been designed such that the TSX spacecraft has to follow the envisaged TerraSAR-X reference orbit characterized by a sun-synchronous dusk-dawn orbit at $514 \mathrm{~km}$ altitude, $97.4^{\circ}$ inclination with a repeat cycle of 11 days. Absolute orbit control of the TerraSAR-X reference orbit is performed by hydrazine thruster maneuvers on TSX which are duplicated on TDX spacecraft in order to minimize influence on relative motion. Formation-keeping maneuvers are performed by the TDX cold gas propulsion system (TSX is not equipped with this propulsion type). For details on absolute and relative orbit control please refer to Kahle et al. $2011^{10}$. The collection of bi-static SAR data for the TanDEM-X digital elevation model is performed in different mission phases. Each mission phase is characterized by different relative orbital elements leading to different inter satellite distances and hence different radiometric baselines. Relative elements may be stable during a mission phase or a drift in relative elements may be introduced. In the closest formation established until now TSX and TDX approached to $150 \mathrm{~m}$ inter satellite distance. This formation was kept from January 2012 until March 2012.

Relative orbit geo. for TanDEM -X mission phase

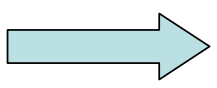

TanDEM -X mission orders

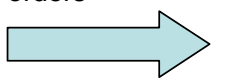

TerraSAR-X mission orders

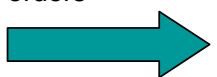

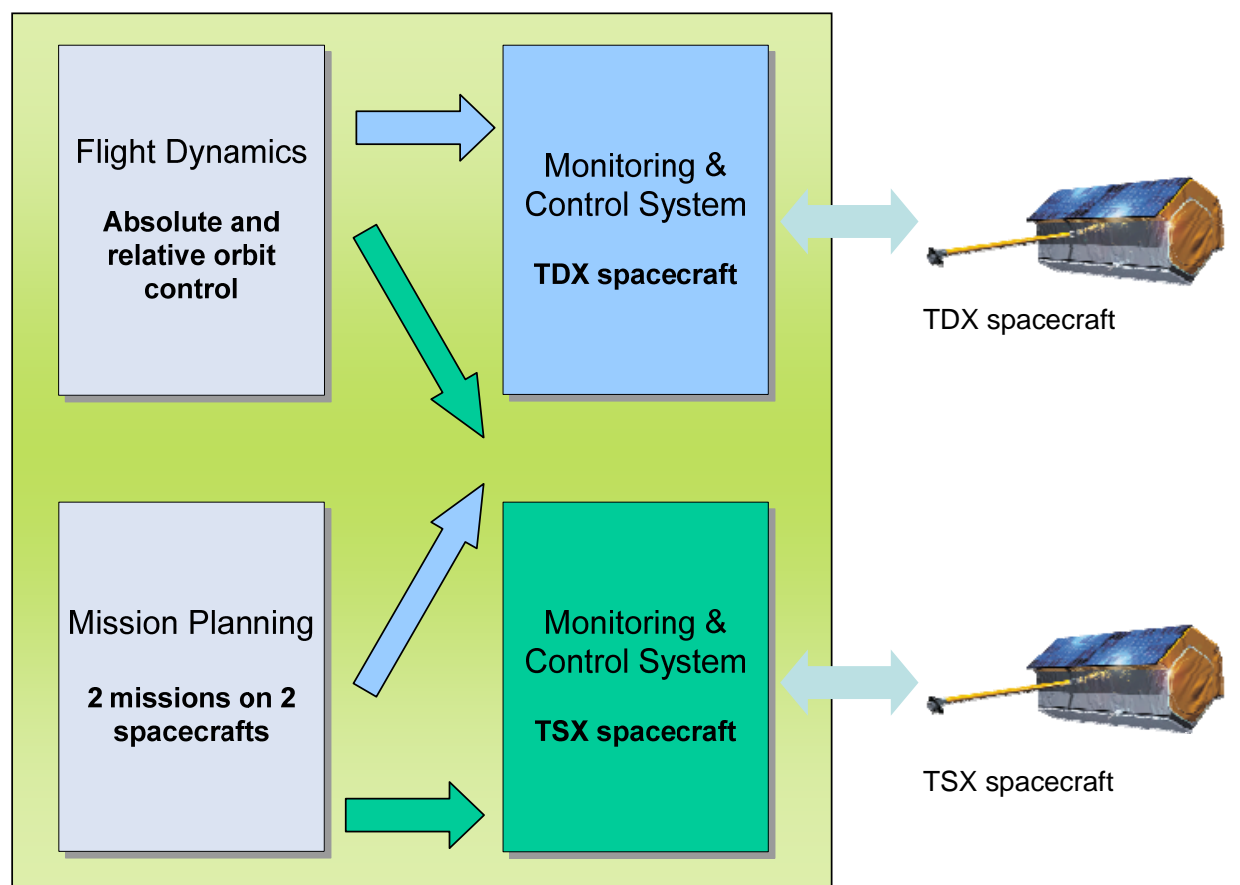

Figure 1. Schematic, simplified workflow for dual satellite/dual mission operations: The outer box summarizes elements being part of the Control Center. TDX and TSX space craft are each controlled by a satellite specific monitoring \& control system. The elements Mission Planning and Flight Dynamics are combined systems for both satellites, generating output to both monitoring \& control systems. The Mission Planning System receives external orders from the TerraSAR-X mission and the TanDEM-X mission. Relative orbit control performed by Flight Dynamics is based on the required geometry of the TanDEM-X mission phase.

The combined TerraSAR-X/TanDEM-X Mission Planning System (MPS) performs a cross coupling of mission specific inputs and satellite specific master timeline outputs. It receives orders from TerraSAR-X mission users and has to schedule TanDEM-X datatakes based on the TanDEM-X acquisition plan. According to on a priority concept the MPS selects from these set of orders a subset and assigns appropriate tasks to both satellites. It schedules monostatic TerraSAR-X mission datatakes on either TSX or TDX and in case of bi-static TanDEM-X datatakes it assigns the "active" and the "passive" role to the satellites. The active one transmits radar beam, active and passive satellite both receive the backscatter from Earth's surface. Parallel TerraSAR-X mission datatakes on TSX and TDX are not possible due to possible interference. A detailed description of the combined TerraSAR-X/TanDEM-X Mission Planning System can be found in Ref. 11. 
Payload data are transmitted to ground in X-Band. TerraSAR-X and TanDEM-X mission have each a separated XBand ground station network. This will be addressed in chapter III. During a common pass of the TSX and TDX formation payload data of the appropriate mission (TanDEM-X or TerraSAR-X) are transmitted sequentially by TSX and TDX to the ground station. This approach, called sequential X-Band downlink, is possible because both satellites use an identical downlink frequency range and the inter satellite distance is small enough that the ground station tracks both satellites at the same time. Mission Planning has to assure that at a given time only one satellite is transmitting X-Band data to avoid interferences. Sequential downlink is the consequence of the combination of the two missions for these two reasons:

TerraSAR-X mission: The sharing of X-Band downlink opportunities between the satellites ensures that the time from an acquisition to the downlink pass does not depend on the satellite. This opens up the possibility to balance TerraSAR-X mission datatakes between TSX and TDX even in case the user has a high demand in quick data delivery.

TanDEM-X mission: Bi-static acquisitions involve both satellites and occupy therefore memory in both spacecraft. Datatakes from both spacecraft are sent to ground during one X-Band downlink opportunity and consequently on both spacecraft these datatakes may be deleted on-board after the downlink pass. This guarantees a balanced way of freeing on-board memory resources on TSX and TDX. Both spacecraft regain sufficient storing capacity for further acquisitions.

\section{Ground Station Network}

As already mentioned in section II, the dual satellite/dual mission operations concept is based on satellite specific S-Band contacts for TT\&C and mission specific X-Band passes for payload data. Figure 2 shows a typical schedule for S-Band passes. The southern German ground station Weilheim (WHM) is the dedicated S-Band ground station for TDX offering in the morning and in the evening normally 2 passes in a row. The counter part for TSX is Neustrelitz (NSG) in northern Germany with two times 2-3 contacts in a row. These TSX and TDX passes are parallel in time due to the proximity of the TSX and TDX orbits. Morning/evening passes are used for parallel uploads of the TSX and TDX master timelines. Usually, the first simultaneous contacts over WHM/NSG are already sufficient for the timeline upload (typically a bit less than 1000 tele-commands per satellite are loaded). The second passes serve as back-up. The generated master timelines for TSX and TDX depend on each other. For example elements like bi-static acquisitions must be executed simultaneously on both satellites and techniques like sequential downlink pose inter satellite constraints to be respected. Therefore master timeline modifications must be performed in a synchronized way. Typically, the timeline is loaded on both satellites a day in advance. Updates to the on-board timeline due to late input are performed, if necessary, after $12 \mathrm{~h}$.

Regular monitoring is done in addition to the above with the ground stations Spitsbergen, Inuvik and O'Higgins (GARS). The schedule of the entire contacts ensures that for both satellites the time between two succeeding passes does not exceed $6 \mathrm{~h}$. Pre-launch analysis showed that a $6 \mathrm{~h}$ rhythm is required for

1) Compliance with safety requirements in close formation flight (detailed in section IV)

2) Timely availability of GPS based orbit data

3) Formation relative orbit control 
Figure 3 shows the mission specific X-Band downlink network. TanDEM-X mission data are downlinked to the stations O’Higgins, Inuvik and Kiruna. TerraSAR-X mission data are primarily downlinked to Neustrelitz.
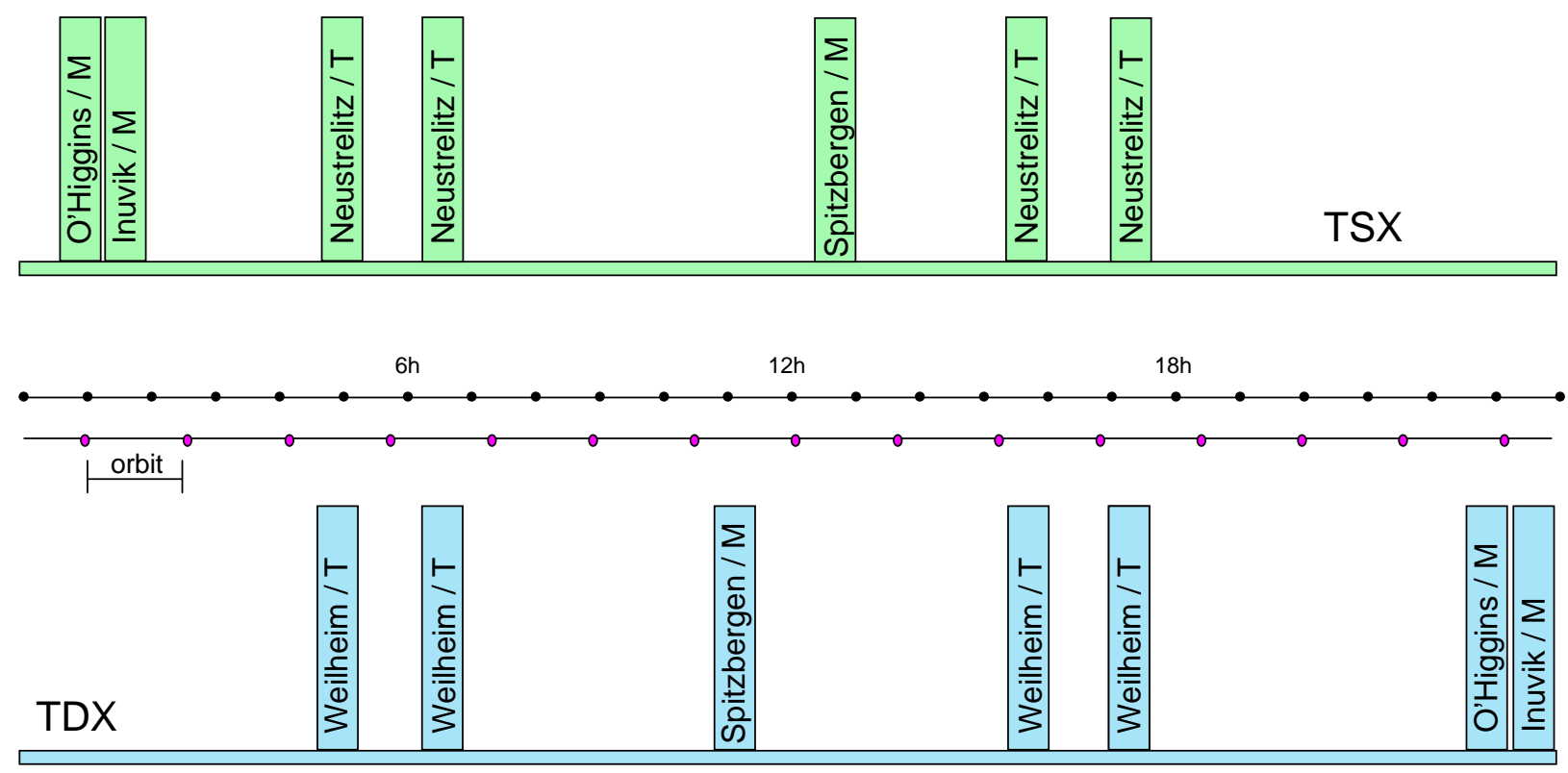

Figure 2. Typical TSX and TDX S-Band passes during one day: Primary S-Band ground stations for TSX is Neustrelitz (Germany) and for TDX Weilheim (Germany). These passes are used for Mission Timeline Upload which is denoted by " $T$ ". Additionally, monitoring passes are requested each day (" $M$ "). These monitoring passes are carried out over Spitsbergen, O'Higgins (Antarctica) and Inuvik (Canada). The width of the bar does not represent the duration of the pass (which is in the order of 10 minutes)

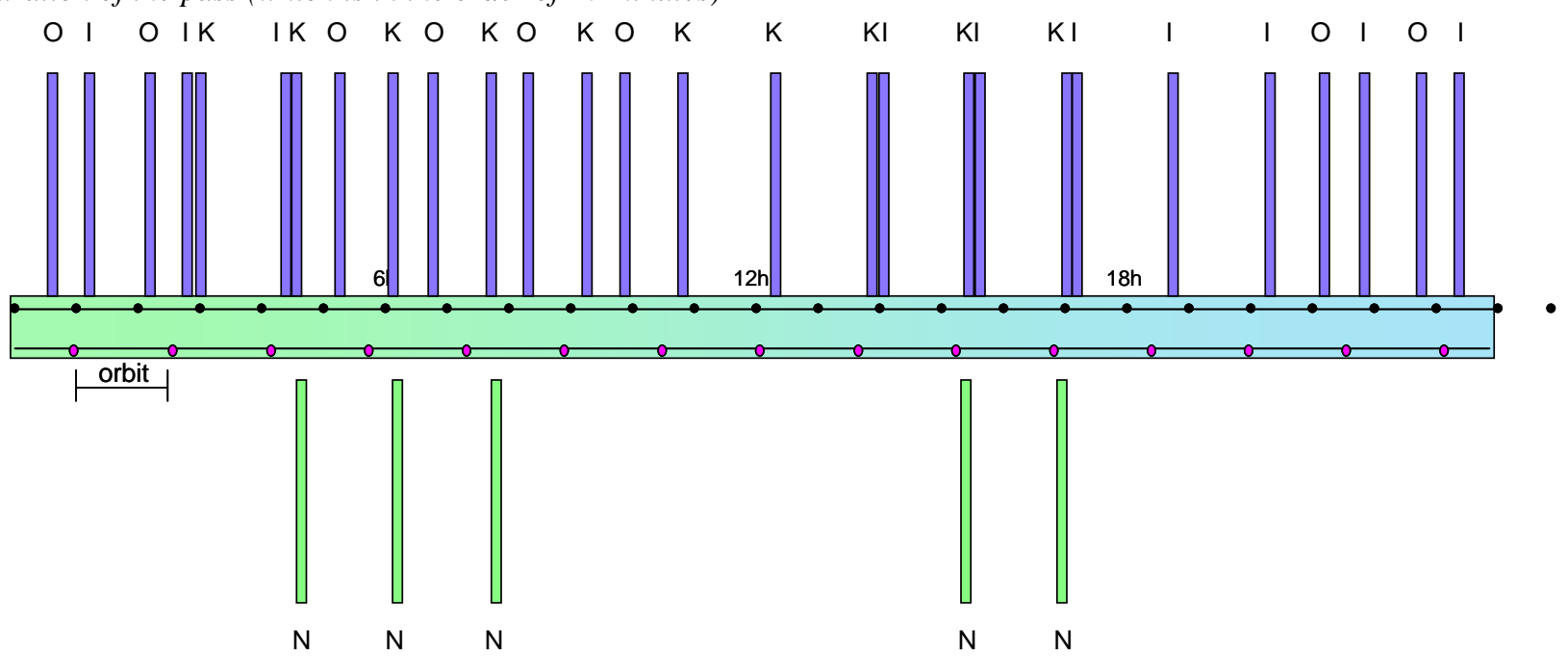

Figure 3. Typical TerraSAR-X mission and TanDEM-X mission X-Band passes during one day: Primary TerraSAR-X mission ground station for $X$-Band downlink is Neustrelitz $(N)$ in northern Germany (additional TerraSAR-X mission $X$-Band downlink stations of the commercial marketer Infoterra are not plotted. TanDEM-X mission downlinks are performed over O'Higgins (Antarctica), Inuvik (Canada) and Kiruna (Sweden). Downlinks to both networks need to be performed by both space crafts TSX and TDX.

Extensions to the TerraSAR-X mission network downlink pool are provided by so called direct access customers of the TerraSAR-X mission data marketer Astrium GeoInformation. The requirements on the network differ with the nature of the mission: The TanDEM-X mission produces high amount of data for the global digital elevation model

6

American Institute of Aeronautics and Astronautics 
(order of 350 TB downlink volume for the DEM ${ }^{12}$ ). TerraSAR-X mission data have often high demand on fast product access. Therefore TerraSAR-X mission data are directly processed at the reception ground stations. TanDEM-X data are stored at the ground station and transported to Oberpfaffenhofen where central processing is performed.

\section{Close formation safety aspects}

TSX and TDX are orbiting in a close formation flight with inter satellite distances of few hundreds meters. Due to a relative separation of the eccentricity and inclination vectors a helix like relative motion is established. For the concept please refer to D'Amico et al. $2006{ }^{14}$. Close to the poles TSX and TDX are separated in radial direction whereas close to the equator crossings the radial separation vanishes and is replaced by a separation in horizontal direction (in nominal direction and in along-track-directions) ${ }^{10}$.

The close formation flight of TSX and TDX incorporate two major risks:

1) Risk of collision

2) Risk of mutual SAR illumination

By design the concept of relative inclination/eccentricity vector separation offers a passive stability of the helix formation for about 10 days as long as both satellites' orbits are not modified by hydrazine thruster usage. Collision risks may be evoked by on-board autonomous usage of thrusters. The original TSX safe mode concept, established for the former single satellite TerraSAR-X mission, foresees the usage of hydrazine thrusters for attitude control in safe mode. As a side affect unintended orbit changes resulted in case of safe mode entry. As a consequence of the TanDEM-X mission the safe mode design has been reworked for TSX and TDX. A magnetic torquer based safe mode which does not affect the satellite orbit has been introduced. Since the reactiveness of the magneto torquer based safe mode is weaker than the one of the original thruster based safe mode, a mixed concept has been chosen: The magnetic torquer based safe mode is configured as the default safe mode and the thruster based safe mode as last resort only ${ }^{15,16,17}$.

Hydrazine orbit control maneuvers are double checked against collision risks covering also possible maneuver failure scenarios. In case a potential failure or underperformance of one or a combination of maneuvers would lead to an approach of the satellites closer than a defined threshold (e.g.150m), the maneuvers are spitted in smaller ones.

In parts of the orbital evolution transmitting radar pulses would lead to illumination of the partner satellite. It has been analyzed that the radiation could cause permanent damage to the partner's SAR payload. As a consequence operational measures have been established in order to avoid radar transmission in these forbidden areas, called Exclusion Zones (EZ). Compliance of the master timeline with the Exclusion Zones is checked in a triple way to minimize the risk: First, the EZ are checked by the Mission Planning System which avoids planning of active SAR datatakes in EZ (passive bi-static datatakes are allowed). Secondly, the master timeline is double checked against illumination risks before upload by an independent application. As a third step an on-board check based on the argument of latitude is established ${ }^{18}$. However, overall payload operations are not restricted due to the EZ since TSX and TDX EZ do not overlap. The satellite being not in EZ can take over TerraSAR-X mission datatakes or the active part in bi-static TanDEM-X acquisitions. The dimensions of the EZs depend on the relative formation geometry. In case of maneuvers the on ground EZ are enlarged to cover for potential maneuver failures. Since a change of the relative orbit geometry causes a change in boundaries of the EZ, all three EZ checks fail in case of the unlikely event of a thruster based safe mode drop causing orbit disturbances. A mechanism to notify the partner satellite of potential orbit disturbances is required. As reaction the partner must immediately suppress the own radar transmission in order to protect the partner from potential harm by illumination.

Due to the shifted schedule of TSX and TDX integration a mono-directional inter satellite link from TSX to TDX could be realized only. The TDX satellite receives TSX GPS based orbit and state, but not vice versa. As compensation for a bi-directional link the sync warning datatake mechanism has been established. It makes use of 
sync horns on TSX and TDX needed for synchronization of instrument phases in bi-static datatakes. Via the sync horns a bi-directional 1 bit information, partner ok or not ok, are exchanged between TSX and TDX. Sync warnings datatakes are scheduled approximately twice per orbit. In case of unsuccessful sync link exchange radar transmission is suppressed to protect the partner since it could have changed its orbit.

\section{Conclusion \& Experiences}

TSX and TDX first were brought in a close helix formation in October 2010 and are still orbiting around the earth in tight proximity. The relative orbital elements have been varied with resulting inter satellite distances from $150 \mathrm{~m}$ to 500m. TerraSAR-X and TanDEM-X mission data are acquired in a work balance between the TSX and the TDX satellites. Support of the TerraSAR-X mission objectives has been continued and the TanDEM-X mapping plan completed the first global coverage in January $2012^{19}$. The formation flight safety mechanism proved to be reliable. The safe mode concept based on magnetic torquers has been tested in orbit on both TSX and TDX in a test period before entering the close formation. Even after commanding to safe mode in non-standard attitude and rotation rate the on-board autonomy was able to recover the situation. During the close formation no safe mode drops have occurred on both satellites so far.

The sync warning mechanism turned out to be very stable. No false alarms happened, and thus radar transmission has not been suppressed without any reason. So far two sync link failures events occurred (in both cases as a consequence of minor contingencies). Further detailed operations experiences are described by Schulze et al. 2012 20 .

\section{Acknowledgments}

The Authors thank colleagues from German Space Operations Center for their engaged work in TerraSARX/TanDEM-X daily operations, the members of DLR Earth Observation Center, DLR Microwaves and Radar Institute and Astrium for the good collaboration within the project. Special thanks to J. Herman for correcting the manuscript.

The TanDEM-X project is partly funded by the German Federal Ministry for Economics and Technology (Förderkennzeichen 50 EE 1035) and is realized in a public-private partnership by DLR e.V. and Astrium EADS.

\section{References}

\footnotetext{
${ }^{1}$ Werninghaus, R., Buckreuss, S., “The TerraSAR-X Mission and System Design”, IEEE Transactions on Geoscience and Remote Sensing, Vol.48, No. 2, 2010, pp. 606-614

${ }^{2}$ Pitz, W., Miller, D., “The TerraSAR-X Satellite” IEEE Transactions on Geoscience and Remote Sensing, Vol.48, No. 2, 2010, pp. 615-622

${ }^{3}$ Buckreuss, S., Schättler, B., “The TerraSAR-X Ground Segment”, IEEE Transactions on Geoscience and Remote Sensing, Vol.48, No. 2, 2010, pp. 623-632

${ }^{4}$ Krieger, G., Zink, M., Schulze, D., Hajnsek, I., Moreira, A., “TanDEM-X: Mission Overview and Status”, Proceedings of the International Conference on Spacecraft Formation Flying Missions \& Technologies (SFFMT), St-Hubert, Canada, 2011, pp.

${ }^{5}$ Moreira, A., Krieger, G., Fiedler, H., Hajnsek, I., Younis, M., Zink, M., Werner, M. “Advanced Interferometric SAR Techniques with TanDEM-X”, Proceedings of the IEEE Radar Conference (RadarCon), Rome, Italy, 2008, pp. 5-9

${ }^{6}$ Moreira, A., Krieger, G., Hajnsek, I., Houman, D., Riegger, S. Settelmeyer E., "TanDEM-X: A TerraSAR-X Add-On Satellite for Single-Pass SAR Interferometry” Proceedings International Geoscience and Remote Sensing Symposium”, Anchorage, USA, 2004, pp. 1000-1003, ISBN 0-7803-8742-2 (Softbound) 0-7803-8743-0 (DVD)

${ }^{7}$ Montenbruck, O., Wermuth, M., Kahle, R., "GPS Based Relative Navigation for the TanDEM-X Mission - First Flight Results”, Navigation, Vol.58, No. 4, 2011, pp. 293-304

${ }^{8}$ Ortega-Miguez,C., Schulze, D., Polimeni, M. D., Boer, J., Rizzoli, P., Bachmann, M.,“TanDEM-X Acquisition Planner”, European Conference on Synthetic Aperture Radar(EUSAR), Nuremberg, Germany, 2012, pp. 5-9

${ }^{9}$ Giese,C., Ulrich, D.,“The TanDEM-X Space Segment”, Geoscience and Remote Sensing IEEE International SymposiumIGARSS, Vancouver, Canada, 2011, pp.2294-2297, 10.1109/IGARSS.2011.6049667

${ }^{10}$ Kahle, R., Schlepp, B., Kirschner, M., "TerraSAR-X / TanDEM-X Formation Control - First results from Commissioning and Routine Operations” Journal of Aerospace Engineering, Sciences and Applications, Vol. 3, No 2, 2011, pp. 16-27
} $1-10$ 
${ }^{11}$ Mrowka, F., Geyer, M. P., Lenzen, C., Spoerl, A., Goettfert, T., Maurer, E., Wickler, M., Schaettler, B. “The joint TerraSAR-X / TanDEM-X mission planning system”, Geoscience and Remote Sensing IEEE International SymposiumIGARSS, Vancouver, Canada, 2011, pp.3971-3974, DOI 10.1109/IGARSS.2011.6050101

${ }^{12}$ Kroeger, S., Schwinger, M., Wegener, M., Wolfmueller, M,“Data Handling and Preservation for the TanDEM-X Satellite Mission”, PV 2009: Ensuring Long-Term Preservation and Adding Value to Scientific and Technical Data, Madrid, Spain, 2009

${ }^{13}$ Breit, H., Fitz, Thomas,Schaettler, B., Balss, U., Damerow, H., Schwarz, E. "TerraSAR-X Payload Data Processing: Results from Commissioning and Early Operational Phase”, Geoscience and Remote Sensing IEEE International SymposiumIGARSS, Boston, USA, 2008

${ }^{14}$ D’Amico S, Montenbruck, O., “Proximity Operations of Formation-Flying Spacecraft Using an Eccentricity/Inclination Vector Separation” Journal of Guidamce, Control and Dynamics, Vol 29, No.3, 2006, pp. 554-563

${ }^{15}$ Herman, J., Schulze, D., Löw, S. "TanDEM-X Close Formation Flight AOCS Safety Measures and Operations", Conference Proceedings $4^{\text {th }}$ International Conference on Spacecraft Formation Flying Missions \& Technology, St.Hubert, Canada, 2011

${ }^{16}$ Zimmermann, R., Fischer, D., Giese, C., Miller, D. "Safety mechanisms for operational formation flight of TerraSAR-X and TanDEM-X”, Conference Proceedings $4^{\text {th }}$ International Conference on Spacecraft Formation Flying Missions \& Technology, St.Hubert, Canada, 2011

${ }^{17}$ Herman, J., Fischer, D., Schulze, D., Loew, S. “AOCS for TanDEM-X Formation flight at 200m separation in low-earth orbit”, SpaceOPS 2010, Huntsville, USA, 2010

${ }^{18}$ Hofmann, H., Kahle, R. "The TanDEM-X Mission Operations Segment: Close formation flight: Preparation and First Experiences”, SpaceOPS 2010, Huntsville, USA, 2010

${ }^{19}$ Buckreuss, S., Zink, M. “TerraSAR-X/TanDEM-X Mission Status”, 2nd EUSC SAR Workshop, Torrejon de Ardoz, Spain, 2012

${ }^{20}$ Buckreuss, S., Zink, M. “TerraSAR-X/TanDEM-X Mission Status”, Proceedings Space OPS 2012, Stockholm, Schweden, 2012 